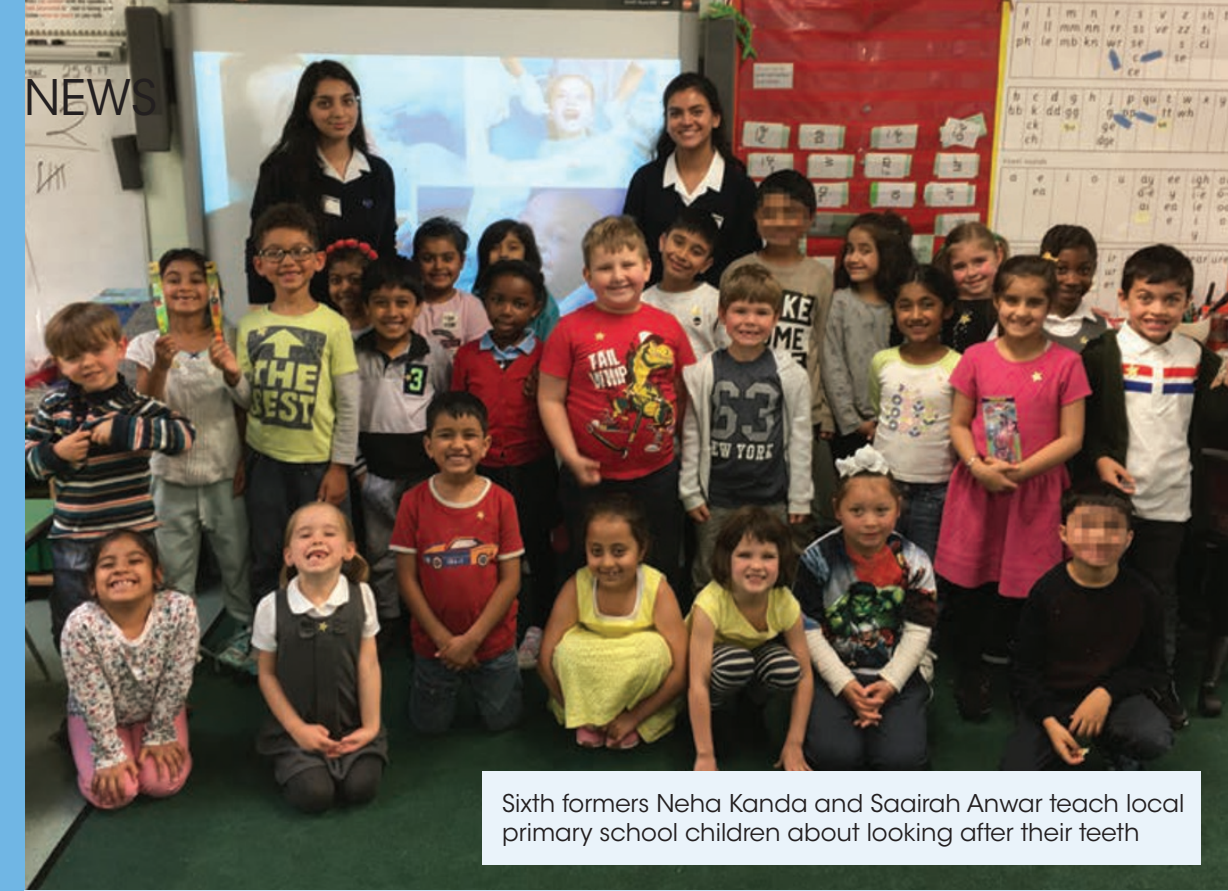

\section{SIXTH FORMER TAKES ORAL HEALTH TO PRIMARY SCHOOL CHILDREN}

\section{By Neha Kanda}

My name is Neha Kanda and I am a sixth form student at Wolverhampton Girls' High School applying for dentistry this October.

While on work experience at various dental practices, the vast disparities in the level of oral health and dental hygiene in children, based upon the socio-economic status of the area, struck me greatly. I spent two weeks at two mixed practices and two weeks at two NHS practices.

With Wolverhampton being within the top 20 most deprived areas in the UK, I initiated a project, following my work experience, to perform a workshop at a local primary school in an area with a particularly low socio-economic status, educating the children about preventative dentistry and maintaining a good standard of dental health in an interactive, informative and memorable way.

The workshop was carried out at Merridale Primary School Wolverhampton with year 2 children, aged 6-7. I was accompanied by my fellow pupil, Saairah Anwar, who hopes to study medicine. Incorporating the tips and advice given to me by Dr Jonathan Lewney, Associate Editor (Science) BDJ Portfolio, I put together and gave the presentation on 25 September, and was commended for carrying out an 'engaging, thoughtful and informative' session.

Ranging from the importance of teeth and a healthy diet, to brushing techniques, fluoride toothpaste and even dental caries, the children interacted well and were eager to learn new information throughout. It was very fulfilling finishing the session knowing that the children had taken something away from the afternoon and were genuinely enthusiastic to put into practice what they had been taught. Beginning the session with the children not even knowing the basics of good oral hygiene, to finishing with a quiz where all 25 children were buzzing with excitement to tell me the correct answer, was one of the most satisfying aspects of the day.

\section{When two dental events become one}

The British Dental Association (BDA) and CloserStill Media have announced a major new collaboration that will see the first 'British Dental Conference and Dentistry Show' launched in May 2018.

The new collaboration of the BDA's British Dental Conference and Exhibition, and CloserStill Media's The Dentistry Show, will take place on 18-19 May 2018 at the Birmingham NEC.

The BDA Conference and Exhibition has been running for over 100 years and is the BDA's annual flagship event for its members and the wider dental team. The Dentistry Show will have been running for 11 years in 2018. The new event will now become the key date in all dental professionals' diaries and will be free of charge and open to all.

BDA Chief Executive Peter Ward said: 'We're committed to offering our members and this profession the biggest and best event in the dental calendar. This collaboration with our friends at CloserStill Media will take our landmark event to the next level.

Alex Harden, Event Director of The Dentistry Show said: 'This is an exciting investment for us all. Between us, the team now running The Dentistry Show and The BDA Conference have been responsible for running some of the UK's fastest growing events over the last two decades. Our combined experience, sector knowledge and significant commercial and marketing resources will be focussed on delivering for both exhibitors and the audiences for these powerful brands'

\section{BSDHT OPENS NEW OFFICES}

The British Society of Dental Hygiene and Therapy (BSDHT) was delighted to officially open its brand new offices in Rugby this September.

To mark the occasion, key supporters from throughout the profession visited the new premises to celebrate the organisation's latest achievement.

Helen Minnery, President of the BSHDT, commented: 'The launch of our new office is a momentous occasion for the
BSHDT. I'd like to say a big thank you to all attendees who represent the trade, both for your support and for your recognition of our profession'.

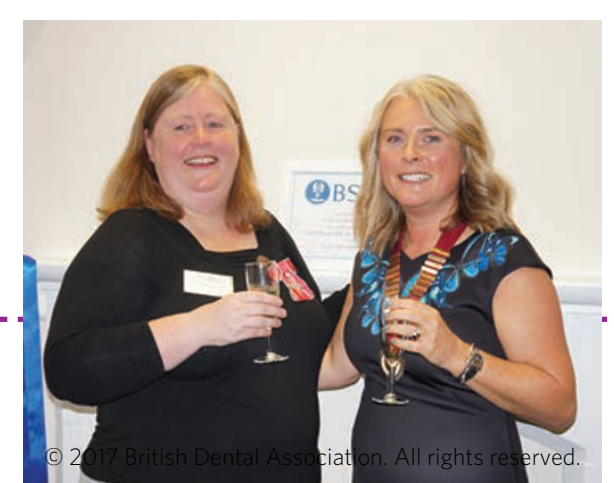

Sarah Murray OBE, elected Council Member of the BSDHT, was invited to officially open the new office. Before cutting the ribbon, she shared a few words about what the BSDHT means to her: 'I really value the BSDHT - it is like an extended family for me as I have been a staunch supporter since I was a student. I think the organisation does a fantastic job of moving our profession onwards. The new office is a real landmark for the BSDHT!'

For more information about the BSDHT, visit www.bsdht.org.uk. 